\title{
Cooling Anesthesia for Intravitreal Injection: Results of the Prospective Open-Label, Dose-Ranging COOL-I Trial
}

\author{
Daniel L Chao' \\ Nicolas T Rinella' \\ Arshad M Khanani ${ }^{2}$ \\ Charles C Wykoff $\left.{ }^{3}\right)^{3}$ \\ Gun-Ho Kim ${ }^{4,5}$ \\ 'Viterbi Family Department of \\ Ophthalmology, University of California, \\ San Diego, CA, USA; ${ }^{2}$ Sierra Eye \\ Associates and University of Nevada, \\ Reno School of Medicine, Reno, NV, \\ USA; ${ }^{3}$ Retina Consultants of Texas, \\ Retina Consultants of America; Blanton \\ Eye Institute, Houston Methodist \\ Hospital \& Weill Cornell Medical College, \\ Houston, TX, USA; ${ }^{4}$ RecensMedical, \\ Ulsan, Korea; ${ }^{5}$ Department of Biomedical \\ Engineering, Ulsan National Institute of \\ Science and Technology, Ulsan, Korea
}

Correspondence: Daniel L Chao; Gun-Ho Kim

Tel +I- 858-534-6290; +82 3I 80433036

Email Daniel.chao3@gmail.com;

gunho.kim@recensmedical.com
Purpose: To evaluate the safety and efficacy of a novel medical device to provide cooling anesthesia to the eye as local anesthesia for intravitreal injections.

Study Design: First in human, open-label study of 43 subjects assessed at three different doses: $-10^{\circ} \mathrm{C}$ for 20 seconds (group 1), $-15^{\circ} \mathrm{C}$ for 15 seconds (group 2), and $-15^{\circ} \mathrm{C}$ for 20 seconds (group 3). Main outcome measures were safety and pain of injection using a numeric rating scale (NRS).

Results: Cooling anesthesia did not result in any serious ocular adverse events. One grade 1 adverse event was a vasovagal response during cooling administration which resolved immediately after cooling. Mean NRS scores at the time of injection for each group ranged from 2.5 to 4.3 There was a statistically significant difference between pain scores of the 3 groups at injection in aggregate but not in pairwise comparisons $(P$ value $=0.047)$. There was a statistically significant decrease in pain from injection to 5 minutes post injection in all groups ( $P$ value $=0.00008,0.003,0.0005$ for groups $1,2,3$, respectively) as well as from 5 minutes to $24-48$ hours $(P$ value $=0.00001,0.018$, and 0.0545 for groups $1,2,3$, respectively).

Conclusion: The rapid cooling anesthesia device was well tolerated for achieving local anesthesia among patients receiving intravitreal injections with no serious ocular adverse events.

Keywords: intravitreal injection, anesthesia, cooling, pain

\section{Introduction}

Intravitreal injections (IVT) have become the most common procedure performed by retina specialists with an estimated 6 million IVTs in 2016. ${ }^{1}$ Given the high volume of IVTs performed, there has been strong interest in optimizing the patient experience as well as the clinical workflow.

A number of studies have demonstrated that patients can have significant anxiety and discomfort during IVT. Studies have observed that the step most associated with significant discomfort and anxiety was the needle penetration itself, versus the preparation or waiting. ${ }^{2,3}$ Current methods of anesthesia for IVTs include topical anesthetic drops, application of a cotton tip applicator soaked with lidocaine, preservative free lidocaine gel, as well as subconjunctival lidocaine injection. All of these methods have advantages and tradeoffs in terms of time of onset of anesthesia as well as patient comfort with no consensus. In the 2019 American Society of Retina Specialists (ASRS) Preferences and Trends (PAT) survey, 23\% of retina 
specialists used topical drops, $18 \%$ used pledgets soaked with lidocaine, $25 \%$ used lidocaine gel, and $34 \%$ used subconjunctival lidocaine injection, ${ }^{4}$ similar to previous published IVT anesthesia surveys. ${ }^{5}$

Prospective studies as well as systematic reviews comparing the efficacy between different methods of anesthesia have been mixed, with the majority suggesting there is no difference in pain scores between these methods of anesthesia. $^{6-11}$ Factors which influence the choice of anesthesia by retina specialists include patient satisfaction, procedure workflow and efficiency, and cost. An alternative method of anesthesia that is well tolerated by patients and has a rapid onset of action may improve both the patient experience as well as clinical workflow.

Using low temperatures as a form of anesthesia for medical applications has been investigated in many settings, and is commonly used as anesthesia for injection of dermal fillers. ${ }^{12,13}$ Mechanisms for anesthesia using low temperature include decreased nerve conduction which inhibits the firing of pain receptors, and release of endorphins. ${ }^{13,14}$ Here, we define the term "cooling anesthesia" as the focal application of temperatures slightly below freezing (usually between -10 and -20 degrees Celsius) as a method of local anesthesia. This temperature is much higher than temperatures that have been shown to cause tissue damage to the eye, such as from cryotherapy. ${ }^{15-17}$ The initial proof of concept that low temperatures could anesthetize the eye was a case report that demonstrated that use of gloved ice applied to the conjunctiva and sclera of the eye for 2 minutes was sufficient to effectively anesthetize the eye for IVT for a patient with a lidocaine allergy. ${ }^{8}$ Additionally, in a randomized open label study, patients administered ice packs for 2 minutes over the eyelid prior to topical anesthesia and injection resulted in statistically significant lower pain scores compared to the control group. ${ }^{18}$ Recently, a clinical study with a prototype cooling device demonstrated that cooling anesthesia was well tolerated, had a rapid onset of action, and pain from cooling anesthesia was not significantly different than lidocaine gel as measured by a visual analog scale (VAS). ${ }^{19}$
To extend this work, a clinical grade next-generation handheld cooling device was developed. In the current manuscript, we report results from a first in human study using this cooling device to evaluate the safety and feasibility of providing local anesthesia for IVT.

\section{Methods}

\section{Study Design}

This trial was a prospective, open-label, dose-escalation clinical trial evaluating the safety of a handheld precision cooling device. The study consisted of a single visit doseescalation study design assessing 3 ascending treatment doses of the cooling anesthesia device: 1$)-10^{\circ} \mathrm{C}$ for 20 seconds, 2) $-15^{\circ} \mathrm{C}$ for 15 seconds, and 3 ) $-15^{\circ} \mathrm{C}$ for 20 seconds. Each study site was responsible for assessing only two of the three treatment doses, with a common dose $\left(-10^{\circ} \mathrm{C}\right.$ for 20 seconds) between the two sites.

Following consent, subjects proceeded with the intravitreal injection as per investigator discretion using the cooling device for anesthesia. $5 \pm 2$ minutes following injection, patient pain was assessed using the Numeric Rating scale (NRS) (Figure 1). Two questions were asked using the following standardized script

On a scale of $0-10$ with 10 being the worse pain you have ever felt in your life, how was your pain 1) during the injection and 2) now, 5 minutes after injection.

A slit lamp biomicroscopy exam and indirect ophthalmoscopy was performed $30 \pm 15$ minutes after the injection to assess for adverse effects. A follow-up phone call 24-48 hours after the injection was then used to assess pain.

Institutional Review Board (IRB) approval was obtained for each study site prior to subject enrollment (Western Institutional Review Board (WIRB) Puyallup, WA). Written informed consent was obtained from all subjects prior to performing any study procedures. The study was performed in accordance with the tenets of the Declaration of Helsinki and Good Clinical Practice

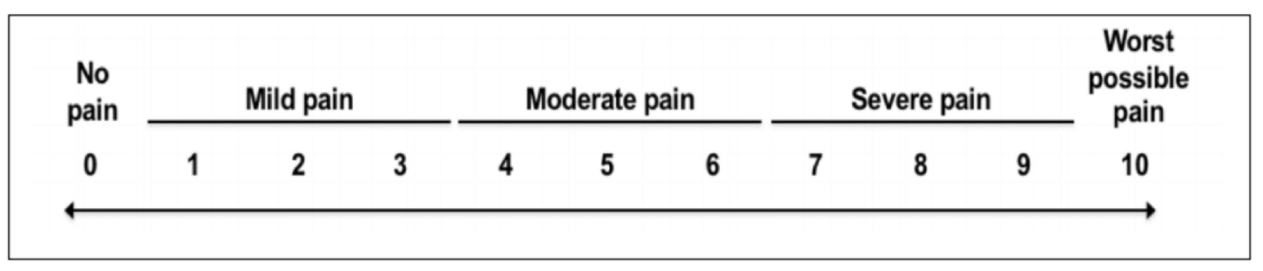

Figure I Numerical Rating Scale used in the COOL-I study. 
guidelines. COOL-1 was registered prospectively at ClinicalTrials.gov (NCT03732287).

\section{Cooling Device}

The device used was a reusable handheld battery-powered device with an attached disposable tip (diameter of $7 \mathrm{~mm}$ ), with the following regulatory certificates: electrical safety test (IEC60601-1), EMC test (IEC60601-1-2), biocompatibility test (ISO10993), cleaning process validation (ISO117371), packaging process validation (ISO11607-1), and validation of sterilization (ISO11137-2006, ASTM F1980-2016, ASTM F88, ASTM F1140, ASTM F1929-15, ASTM F2096-11) (Figure 2). The device provides the cooling temperature to the eye surface at a precision of $\pm 2^{\circ} \mathrm{C}$. The accuracy and precision of the device cooling temperature were found to remain unaffected after one thousand uses at an ambient temperature ranging from $10^{\circ} \mathrm{C}$ and $27^{\circ} \mathrm{C}$.

\section{Study Participants}

Subjects 18 years of age or older were eligible if they were undergoing unilateral IVT using an FDA-approved antiVEGF pharmaceutical as part of their standard of care management, and had previously received a minimum of 3 prior IVT. Subjects were excluded from the study if they had severe dry eye and conjunctival, episcleral or scleral pathologies.

\section{Injection Procedure}

The injection procedure was performed by first instilling one drop of $0.5 \%$ proparacaine into the eye to allow for application of the device to the ocular surface. A lid speculum or manual opening of the lids was then used to expose the eye for injection. Betadine was then applied to the site of injection. The cooling device was then applied between 10 and 20 seconds adjacent to the corneal limbus. A visible, transient scleral indentation was present after cooling administrations. Another drop of betadine was applied and the injection was performed within 30 seconds of the anesthesia within the scleral indentation, indicating the area which was anesthetized. A 30 gauge $1 / 2$ inch needle was used for all injections.

\section{Outcome Measures}

The primary outcome measure of this study was safety as assessed by adverse effects during cooling anesthesia and slit lamp examination and dilated indirect ophthalmoscopy after the injection procedure. Adverse events were graded using the Common Terminology Criteria for Adverse Events (CTCAE) ${ }^{20}$ Secondary endpoints included pain during the intravitreal injection as assessed by the participant's response to a 11-point visual NRS after the procedure (Figure 1). This is a previously validated outcome measure used to evaluate pain of intravitreal injections in similar studies (Clinical trials.gov, NCT01926977). Additional pain outcome measures that were analyzed in this study included the participant's pain NRS score of the intravitreal injection at timepoints of 5 minutes and 24-48 hours after the procedure, as assessed by verbal assessment. Time for the total injection procedure was also recorded.

\section{Statistical Analysis}

Descriptive statistics of pain score outcomes were calculated with means and standard deviations. One-way ANOVA analysis with Tukey's multiple comparisons was used to compare pain outcomes between dose groups. Results of quantitative analysis were plotted and include 95\%

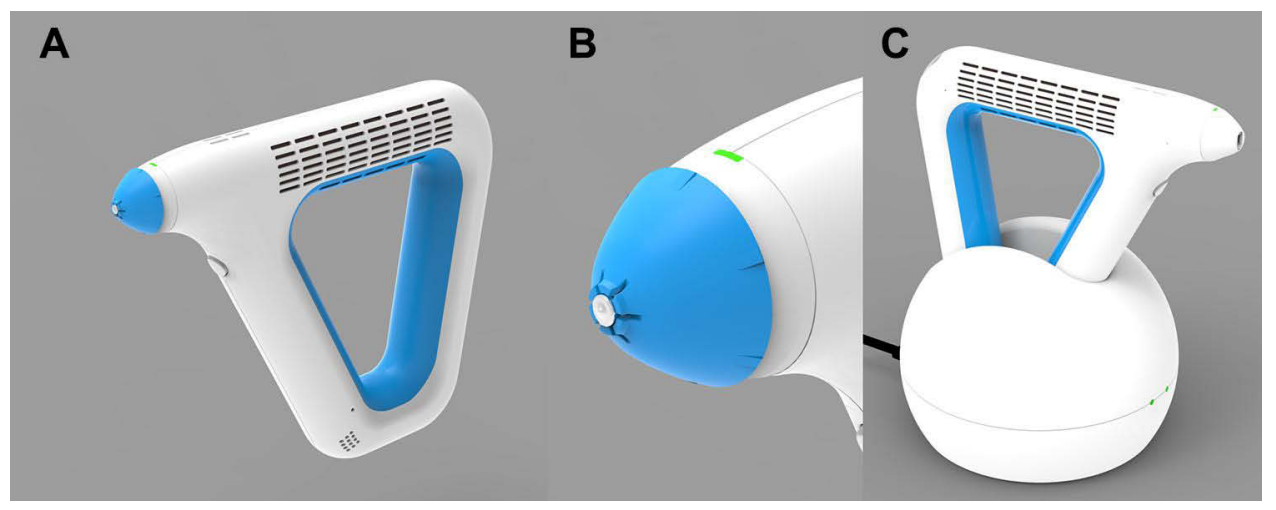

Figure 2 The components of the Cooling Anesthesia Device. (A) The hand-held device, which cools the single-use tips through a high performance thermoelectric cooling module powered by rechargeable batteries. (B) A single-use tip, which includes metal surface delivering the cooling treatment to the conjunctiva for instant anesthetic effect. (C) The battery charging dock, which is used to recharge the device. 
confidence interval error bars. For all analyses, $P$ values $\leq 0.05$ were considered statistically significant. Analyses were conducted in Prism 8 (GraphPad Software, San Diego, CA). As this was a first in human study designed for safety, no formal sample size calculation was performed.

\section{Results}

\section{Study Participants}

A total of 43 subjects were enrolled into the study. Demographics are presented in Table 1. Patients had received a mean of 22.6 (range 3 to 44 ) prior IVTs prior to COOL-1 enrollment, and had received subconjunctival injection of lidocaine as their anesthetic for all previous injections.

\section{Safety}

Cooling anesthesia at all doses was well tolerated. Of the 43 cooling anesthesia applications performed during this study, there was one occurrence of an unexpected Grade 1 adverse event thought to be related to the cooling event. While receiving the $-10^{\circ} \mathrm{C}$ for 20 seconds cooling application, this subject experienced a vasovagal response. The

Table I COOL-I Subject Demographics

\begin{tabular}{|c|c|}
\hline Demographics & Number \\
\hline Men, n (\%) & $24(55.8)$ \\
\hline Women, n (\%) & $19(44.2)$ \\
\hline Age at screening, yrs, mean $\pm S D$, (range) & $70.8 \pm 13.8(33,93)$ \\
\hline \# of previous injections, mean $\pm S D$, (range) & $22.6 \pm 12.7(3,44)$ \\
\hline AMD, n (\%) & $26(60.4)$ \\
\hline DME n, (\%) & $12(27.9)$ \\
\hline RVO n, (\%) & $4(9.3)$ \\
\hline DR n (\%) & $\mathrm{I}(2.4)$ \\
\hline
\end{tabular}

event was transient and completely resolved without treatment. There were no other serious adverse events, or serious ocular adverse events (Table 2). Of note, there was no evidence of conjunctival thinning, scleral thinning, or corneal damage after cooling administration.

\section{NRS Pain Scores}

The mean NRS pain score \pm SD scores at the time of injection are found in Table 3 . There were no statistically significant pairwise group differences in pain scores at injection (Figure 3). However, there was a statistically significant difference between the 3 group measures of pain at injection in aggregate (One way ANOVA, $P$ value $=0.047$ ). There were no statistically significant differences in pain scores between groups 5 minutes post injection or $24-48$ hours post injection (One way ANOVA $P$ value $=0.676$ for 5 min post injection, and 0.32 for pain $24-48$ hours) (Figure 3). NRS pain scores were also compared over time for each group. There was a statistically significant decrease in the pain score at the time of injection to the pain score 5 minutes post injection in all groups (paired $t$ test, $P$ value $=0.00008,0.003,0.0005$ for $-10^{\circ} \mathrm{C}$ for 20 seconds, $-15^{\circ} \mathrm{C}$ for 15 seconds, and $-15^{\circ} \mathrm{C}$ for 20 seconds respectively) (Figure 4, Table 3). There was a statistically significant difference between pain scores 5 minutes post injection and pain scores $24-48$ hours post injection in the $10^{\circ} \mathrm{C}$ for 20 seconds and $-15^{\circ} \mathrm{C}$ for 15 seconds, but not in the $-15^{\circ} \mathrm{C}$ for 20 seconds (paired $t$ test; $P$ value $=$ $0.00001,0.018$, and 0.0545 for $-10^{\circ} \mathrm{C}$ for 20 seconds, $-15^{\circ} \mathrm{C}$ for 15 seconds, and $-15^{\circ} \mathrm{C}$ for 20 seconds respectively) (Figure 4).

\section{Time of Injection}

The time to perform injection from the start of the injection procedure (adding drop of proparacaine to finishing the injection) was recorded for all injections. Mean time for the injection procedure was 2.05 minutes, with a standard deviation of 1.75 minutes.

Table 2 Adverse Events. Parenthesis is Percentage Among All Cooling Applications $(n=43)$

\begin{tabular}{|l|c|c|c|}
\hline Adverse Event & $-10^{\circ} \mathbf{C}$ for 20 Seconds \\
$(\mathbf{n = 2 0 )}$ & $-15^{\circ} \mathrm{C}$ for 15 Seconds \\
$(\mathbf{n}=14)$ & $\begin{array}{c}-15^{\circ} \mathrm{C} \text { for } 20 \text { Seconds } \\
(\mathbf{n}=9)\end{array}$ \\
\hline Ocular AE & 0 & 0 & 0 \\
\hline Serious ocular AE & 0 & 0 & 0 \\
\hline Syncope & $1(2.3)$ & 0 & 0 \\
\hline Endophthalmitis & 0 & 0 & 0 \\
\hline Corneal Abrasion & 0 & 0 & 0 \\
\hline
\end{tabular}


Table 3 Comparison of NRS Pain Scores Among Differing Groups

\begin{tabular}{|c|c|c|c|c|}
\hline Group & $\begin{array}{c}-10^{\circ} \mathrm{C} \text { for } 20 \\
\text { Seconds }\end{array}$ & $\begin{array}{c}-15^{\circ} \mathrm{C} \text { for } 15 \\
\text { Seconds }\end{array}$ & $\begin{array}{c}-15^{\circ} \mathrm{C} \text { for } 20 \\
\text { Seconds }\end{array}$ & $\begin{array}{c}\text { One-Way } \\
\text { ANOVA Score } \\
\text { P value }\end{array}$ \\
\hline $\begin{array}{l}\text { Pain during cooling } \\
\text { application (mean } \pm S D \text { ) }\end{array}$ & $2.7 \pm 2.15$ & $2.75 \pm 1.64$ & $3.89 \pm 3.0$ & \\
\hline $\begin{array}{l}\text { Pain score at time of } \\
\text { injection (mean } \pm S D)\end{array}$ & $3.7 \pm 2.5$ & $2.5 \pm 1.7$ & $4.3 \pm 1.8$ & 0.13 \\
\hline $\begin{array}{l}\text { Pain score } 5 \text { minutes post } \\
\text { injection (mean } \pm S D)\end{array}$ & $1.2 \pm 1.3$ & $1.2 \pm 2.1$ & $1 . I \pm 1.1$ & 0.27 \\
\hline $\begin{array}{l}\text { Pain score } 24-48 \text { hours } \\
\text { post injection (mean } \pm S D \text { ) }\end{array}$ & $0.1 \pm 0.3$ & $0.6 \pm 1.4$ & $0.1 \pm 0.4$ & 0.53 \\
\hline
\end{tabular}

\section{Discussion}

In this first in human clinical study, the safety of a clinical grade precision cooling device was evaluated across multiple treatment regimens. Cooling anesthesia during IVT offers potential advantages over current methods of anesthesia, including rapid onset of action and a nonpharmacologic approach. The current study consisted of subjects who had received multiple prior IVTs, all with subconjunctival lidocaine as their previous anesthetic.

Multiple studies on cryotherapy on human eyes suggest that the cooling temperatures used in the current study do not cause damage to the eye. Rabbit studies on corneal endothelial viability were assessed following application of cryotherapy to the cornea at various temperatures for 20 seconds. No endothelial cell loss was detected at $-10{ }^{\circ} \mathrm{C}$ with largely reversible cell loss observed at $-20^{\circ} \mathrm{C}^{21}$ Another study by Maumenee et $\mathrm{al}^{22}$ applied a cryotip at $-78{ }^{\circ} \mathrm{C}$ to a rabbit cornea for 5 seconds ( $6 \mathrm{~mm}$ treatment spot) and reported cellular damage within the first 5 days that completely resolved at days 10 and 12 . Based on this literature, we incorporated cooling temperatures (maximum of $-20^{\circ} \mathrm{C}$ ) that have not caused irreversible damage to eye tissue in preclinical animal models. ${ }^{21}$

The results of the current study indicate that the device was well tolerated with no serious adverse events or serious ocular adverse events. No signs of conjunctival scarring or thinning with this single administration were observed. One grade 1 adverse event occurred among 43 cooling administrations, a transient vasovagal response that resolved without intervention. Various physiological responses, such as the oculocardiac reflex which can result in bradycardia have been observed with intravitreal injections which potentially could lead to a vasovagal response. ${ }^{23}$ We believe that this adverse event is related to the cooling anesthesia, as this response began during cooling administration. Further work will need to evaluate the incidence of this event; we have not observed a vasovagal response in more than 200 additional cooling applications using the same device in a different clinical trial. $^{24}$

The NRS scale was used as patients with poor visual acuity from some of these diseases may not have sufficient visual acuity to accurately use the VAS score. These pain
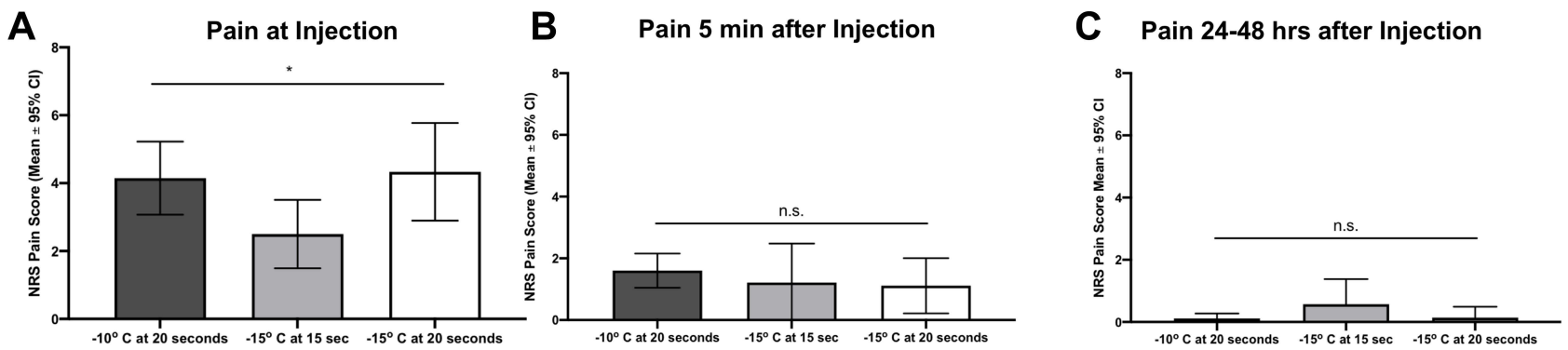

Figure 3 Numerical Rating Scale scores between different cooling treatments. (A) Numerical Rating Scale (NRS) scores at time of injection. Bars are illustrated as mean with $95 \%$ confidence intervals as error bars. (B) NRS scores 5 minutes after Injection. Bars are illustrated as mean with $95 \%$ confidence intervals as error bars. (C) NRS scores 24-49 hours after injections. Bars are illustrated as mean with $95 \%$ confidence intervals as error bars. $* P<0.05 \mathrm{n}$.s. not statistically significant, as measured by one way ANOVA. 


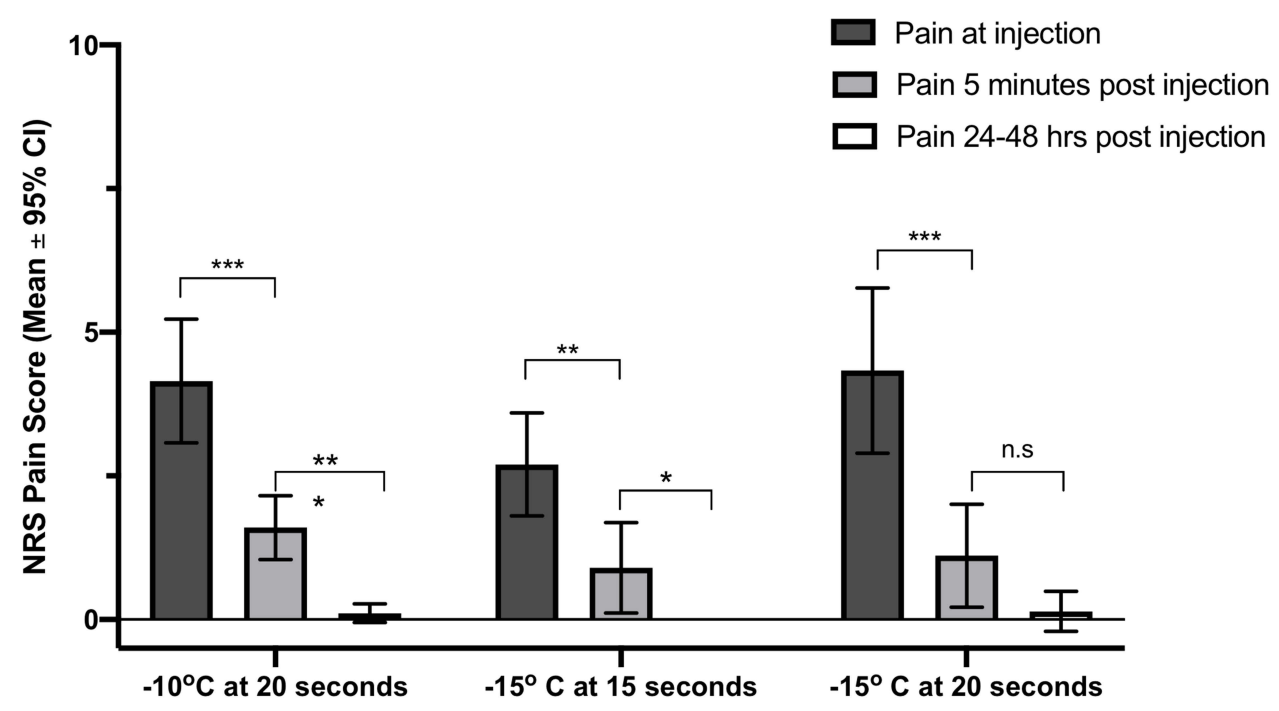

Figure 4 Numerical Rating Scale (NRS) scores over time. NRS scores at time of injection, 5 minutes after injection, and $24-48$ hours injection for each group. Bars are illustrated as mean with $95 \%$ confidence intervals as error bars. $* P<0.05, * * P<0.01$, $* * * P<0.001$, as measured by paired $t$-test.

scores are in a similar range of pain scores reported from other prospective studies evaluating anesthetic agents during IVTs. ${ }^{10}$ While this study was not powered to detect differences in pain scores between different cooling regimens, we did not observe any statistically significant difference of pain scores at the time of injection in pairwise comparisons between the three groups. It should also be noted that the sensitivity of this pain scale to detect small changes in pain perception is unknown. Of note, all three cooling regimens resulted in a rapid decrease in pain scores at 5 minutes and pain scores were minimal 24-48 hours after injection, suggesting that cooling anesthesia did not cause lasting pain.

A single drop of $0.5 \%$ proparacaine was applied before cooling anesthesia application. While proparacaine rapidly anesthetizes the ocular surface, the cooling device simultaneously cools the eye surface including the sclera within 10 seconds, providing rapid and sufficient anesthetic effect for IVT. Thus, one potential benefit of the cooling device is that cooling anesthesia can be applied immediately after instillation of the topical anesthetic, allowing one to perform IVT immediately after examination, which may have benefits for patients and physicians. We found that the average time required for IVT from start to finish was approximately $2 \mathrm{~min}$ utes, which may be considerably faster than other times for IVT using other types of anesthesia, particularly for lidocaine gel and subconjunctival lidocaine, which generally requires 5-15 minutes to achieve maximal clinical effect. These characteristics may affect the patient experience of injection, which may be an important consideration. Future studies are indicated to quantify the effect on patient experience, and to determine if patients may prefer this type of anesthesia compared to other methods. It should be noted, however, that this short time (eg, 2 minutes) could lead to confounding contribution of proparacaine to the NRS pain scores, as topical anesthetic can also anesthetize the eye surface for intravitreal injection.

There are multiple limitations to the present study. The study was not powered to determine differences between treatment regimens. The sample size used in this study is representative of a first in human clinical trial. Future studies will need to address potential confounders such as the study population (patient diagnosis and concomitant medications), pain due to betadine application, and previous anesthetic used. Furthermore, this study was unblinded and did not use a control group. A randomized, masked trial will need to be performed to assess the efficacy of cooling anesthesia compared to other methods of anesthesia for IVTs.

In summary, the cooling anesthesia used in the current study was safe and well tolerated for patients receiving IVT as standard of care management for their retinal disease. The specific properties of cooling anesthesia, particularly its rapid onset of action, may offer unique benefits for the patient experience. Further investigation is needed to understand the long-term effects of repeated cooling 
anesthesia use, and its effectiveness compared to current standard of care anesthetics.

\section{Data Sharing Statement}

The authors do not plan to share deidentified patientlevel data given this data is for an investigational device that has not been approved by any regulatory authorities.

\section{Acknowledgment}

The authors would like to thank all study participants who were willing to volunteer their time to make this clinical trial possible.

\section{Funding}

This study is funded by the study sponsor, RecensMedical Inc. D.L.C is also supported by K08 K08EY030510.

\section{Disclosure}

A.M.K and C.C.W are consultants to RecensMedical, Inc. D.L.

C. was a consultant for RecensMedical, Inc. during the conduct of the study and is now affiliated with Janssen Research and Development, Raritan, NJ, USA. D.L.C also reports personal fees from DTx Pharma, Visgenx; grants from Ionis, Apellis, National Institutes of Health, Chengdu Pharmaceuticals, and Genentech, outside the submitted work. G.H.K. is an employee of RecensMedical, owns equity in RecensMedical, and has a patent $15 / 828,449$ issued to RecensMedical. N.T.R reports personal fees from RecensMedical, outside the submitted work. C.C.W reports personal fees and/or grants from Adverum, Aerie Pharmaceuticals, Aldeyra, Alimera Sciences, Allergan, Allgenesis, Amgen, Annexon, Apellis, Arrowhead, Asclepix, Bausch + Lomb, Bayer, Bionic Vision Technologies, Boehringer Ingelheim, Chengdu Kanghong Biotechnology, Clearside Biomedical, EyePoint Pharmaceuticals, Gemini, Genentech, Graybug, Gyroscope, IONIS Pharmaceutical, iRENIX, IVERIC Bio, Janssen, Kato, Kodiak Sciences, Long Bridge Medical, Lowy Medical Research Institute, Nanoscope, Neurotech, NGM Biopharmaceuticals, Novartis, OccuRx, Ocular Therapeutix, ONL Therapeutics, Opthea, Oxurion, Palatin, Polyphotonix, RecensMedical, Regeneron, RegenXBio, Roche, SamChunDang Pharm, Surrozen, Taiwan Liposome Company, Takeda, Verana Health, Visgenx, Vitranu, Xbrane BioPharma, Aerpio, and Samsung Bioepis, outside the submitted work. The authors report no other conflicts of interest in this work.

\section{References}

1. Williams GA. Intravitreal injections: health policy implications. Rev Ophthalmol. 2014. Available from: https://www.reviewofophthalmology. com/article/ivt-injections-health-policy-implications. Accessed December 05, 2021.

2. Sanabria MR, Montero JA, Losada MV, et al. Ocular pain after intravitreal injection. Curr Eye Res. 2013;38(2):278-282. doi: $10.3109 / 02713683.2012 .758290$

3. Martel A, Nahon-Esteve S, Martini K, Almairac F, Baillif S. Feelings, preoperative anxiety, and need for information in patients undergoing intravitreal injections. Graefes Arch Clin Exp Ophthalmol. 2020;258(7):1395-1403. doi:10.1007/s00417-02004699-4

4. Stone TW, Han P, eds. ASRS 2019 preferences and trends membership survey; oral presentation. Am Soc Retina Specialists. 2019. Available from: https://www.asrs.org/asrs-community/pat-survey. Accessed December 08, 2021.

5. Chaturvedi R, Wannamaker KW, Riviere PJ, Khanani AM, Wykoff CC, Chao DL. Real-world trends in intravitreal injection practices among American retina specialists. Ophthalmol Retina. 2019;3(8):656-662. doi:10.1016/j.oret.2019.03.023

6. Blaha GR, Tilton EP, Barouch FC, Marx JL. Randomized trial of anesthetic methods for intravitreal injections. Retina. 2011;31 (3):535-539. doi:10.1097/IAE.0b013e3181 eac724

7. Cohen SM, Billiris-Findlay K, Eichenbaum DA, Pautler SE. Topical lidocaine gel with and without subconjunctival lidocaine injection for intravitreal injection: a within-patient study. Ophthalmic Surg Lasers Imaging Retina. 2014;45(4):306-310. doi:10.3928/23258160-2014070906

8. Davis MJ, Pollack JS, Shott S. Comparison of topical anesthetics for intravitreal injections: a randomized clinical trial. Retina. 2012;32 (4):701-705. doi:10.1097/IAE.0b013e31822f27ca

9. Yau GL, Jackman CS, Hooper PL, Sheidow TG. Intravitreal injection anesthesia-comparison of different topical agents: a prospective randomized controlled trial. Am J Ophthalmol. 2011;151(2):333-337 e332. doi:10.1016/j.ajo.2010.08.031

10. Han J, Rinella NT, Chao DL. Anesthesia for intravitreal injection: a systematic review. Clin Ophthalmol. 2020;14:543-550. doi:10.2147/ OPTH.S223530

11. Shiroma HF, Nunes RP, Farah ME, et al. Safety and efficacy of various concentrations of topical lidocaine gel for intravitreal injection. Expert Opin Drug Saf. 2014;13(10):1299-1303. doi:10.1517/14740338.2014.947261

12. Sarifakioglu N, Sarifakioglu E. Evaluating the effects of ice application on the pain felt during botulinum toxin type-a injections: a prospective, randomized, single-blind controlled trial. Ann Plast Surg. 2004;53(6):543-546. doi:10.1097/01.sap.0000139563.51598.75

13. Smith KC. Ice anesthesia for injection of dermal fillers. Dermatologic Surg. 2010;36(1):812-814. doi:10.1111/j.1524-4725.2010.01549.x

14. Ernst E, Fialka V. Ice freezes pain? A review of the clinical effectiveness of analgesic cold therapy. J Pain Symptom Manage. 1994;9 (1):56-59. doi:10.1016/0885-3924(94)90150-3

15. Curtin VT, Fujino T, Norton EW. Comparative histopathology of cryosurgery and photocoagulation: Observations on the advantages of cryosurgery in retinal detachment operations. Arch Ophthalmol. 1966;75(5):674-682. doi:10.1001/archopht.1966.00970050676018

16. Garamy G. Engineering aspects of cryosurgical instruments employing liquid nitrogen. Int Ophthalmol Clin. 1967;7(2):283-308.

17. Lee SJ, Choi S, Kim MS, et al. Short-term effect of cryotherapy on human scleral tissue by atomic force microscopy. Scanning. 2013;35 (5):302-307. doi:10.1002/sca.21068

18. Yahalomi T, Hecht I, Lagstein O, et al. Reduction of postintravitreal injection pain using ice: an open-label interventional randomized controlled trial. Retina. 2020;40(7):1434-1438. doi:10.1097/ IAE.0000000000002608 
19. Besirli CG, Smith SJ, Zacks DN, et al. Randomized safety and feasibility trial of ultra-rapid cooling anesthesia for intravitreal injections. Ophthalmol Retina. 2020;4:979-986. doi:10.1016/j. oret.2020.04.001

20. Common terminology criteria for adverse events Version 5.0. Available from: https://ctep.cancer.gov/protocoldevelopment/electro nic_applications/ctc.htm. Accessed December,2021.

21. Chi HH, Kelman CD. Histopathology of corneal endothelium after freezing. Int Ophthalmol Clin. 1967;7(2):369-380.
22. Maumenee AE, Kornblueth W. Regeneration of the corneal stroma cells; review of literature and histologic study. Am J Ophthalmol. 1949;32(8):1051-1064. doi:10.1016/0002-9394(49)90647-9

23. Paciuc-Beja M, Meizner-Grezemkovsky D, Paciuc M, et al. Oculocardiac reflex during intravitreal injection. Med Hypothesis Discov Innov Ophthalmol. 2020;9(2):111-117.

24. Chao DL, Khanani AM, Wykoff CC, Kim G. Cooling anesthesia for intravitreal injection with a novel device: results of the prospective COOL-2 Study. Am Soc Retina Specialists. 2020.

\section{Publish your work in this journal}

Clinical Ophthalmology is an international, peer-reviewed journal covering all subspecialties within ophthalmology. Key topics include: Optometry; Visual science; Pharmacology and drug therapy in eye diseases; Basic Sciences; Primary and Secondary eye care; Patient Safety and Quality of Care Improvements. This journal is indexed on PubMed

Submit your manuscript here: https://www.dovepress.com/clinical-ophthalmology-journal
Central and CAS, and is the official journal of The Society of Clinical Ophthalmology (SCO). The manuscript management system is completely online and includes a very quick and fair peer-review system, which is all easy to use. Visit http://www.dovepress.com/ testimonials.php to read real quotes from published authors. 